- Revista de Iniciação à Docência, v. 2, n. 1, 2017 Publicação: dezembro, 2017 - ISSN 2525-4332

\title{
A SUPERVISÃO COMO POSSIBILIDADE DE FORMAÇÃO INICIAL E CONTINUADA DE PROFESSORES
}

Alisson da Silva Souza ${ }^{1}$

\begin{abstract}
RESUMO: O presente texto apresenta algumas reflexões sobre o trabalho de supervisão realizado no subprojeto "Tecendo histórias e formando professores: memórias, contos e encantos nas expressões sócio-culturais e históricas no cotidiano dos afro-brasileiros" do Programa Institucional de Bolsas de Iniciação à Docência (PIBID), desenvolvido no Campus $V$ da Universidade Estadual da Bahia (UNEB), na cidade de Santo Antônio de Jesus - Bahia. O texto discute as potencialidades do PIBID enquanto dispositivo de formação e reafirma o valor do referido Programa como uma política pública de valorização da carreira docente. Portanto, neste trabalho defendo a importância da supervisão para a formação inicial dos bolsistas e como experiência de reflexão para a formação continuada do próprio professor supervisor.
\end{abstract}

Palavras-Chave: Supervisão; Formação Inicial; Formação Continuada; PIBID.

\section{Primeiras Palavras}

Quero dizer aos leitores e leitoras que este texto é carregado de significados e impressões pessoais. Durante todo o texto, de forma proposital, me coloco em primeira pessoa pois falo enquanto um eterno aprendiz que entende que o tornar-se professor é um processo que se faz durante toda a vida e leva em conta todas as experiências.

Este trabalho é resultado de minha experiência enquanto supervisor do subprojeto "Tecendo Histórias e formando professores: Memórias, contos e encantos nas expressões sócio-culturais e históricas no cotidiano dos afro-brasileiros" do Programa Institucional de Bolsas de Iniciação à Docência (PIBID), desenvolvido no Campus V da Universidade Estadual da Bahia (UNEB), na cidade de Santo Antônio de Jesus - Bahia. O texto intenciona trazer para o debate as reflexões que foram geradas a partir de minha experiência com os bolsistas de iniciação à docência, bem como, pretende salientar a importância da supervisão como um instrumento de formação continuada para o próprio professor supervisor.

Durante os quatro anos que estive na condição de supervisor vivenciei a oportunidade de repensar minha formação, o que me permitiu uma compreensão mais sensível dos limites e das possibilidades que o trabalho de supervisão me

\footnotetext{
${ }^{1}$ Graduado em Psicologia pela Universidade Federal do Recôncavo da Bahia (UFRB), mestrando em Educação pela Universidade Estadual de Feira de Santana (UEFS); professor da rede pública de ensino da cidade de Santo Antônio de Jesus - Bahia. E-mail: pot_ppb@hotmail.com
} 
- Revista de Iniciação à Docência, v. 2, n. 1, 2017 Publicação: dezembro, 2017 - ISSN 2525-4332

apresentava. Para além disso, o fato do projeto ser desenvolvido por estudantes do curso de licenciatura em História serviu para a construção do entendimento de que o tornar-se professor não é um processo apenas dos estudantes de Pedagogia, mas deve contemplar todos aqueles que pretendem adentrar nos espaços escolares.

Duas inquietações me motivaram a escrever este texto. A primeira está relacionada a minha própria formação enquanto professor e pesquisador, em exercício nos anos iniciais da educação básica. A segunda preocupação, diz respeito ao cuidado no que se refere à formação do professor para o fazer docente, tendo em vista que as licenciaturas em áreas específicas têm se dedicado à formação de especialistas, conforme o curso oferecido, o que de certa forma negligencia a dimensão pedagógica da prática docente.

Partindo dessa premissa o texto se propõe a problematizar a importância da supervisão enquanto possibilidade de formação inicial para os bolsistas de iniciação à docência e de formação continuada para o professor supervisor, discute-se também a relação entre teoria e prática no âmbito da escola, que espera dos novos profissionais uma formação mais complexa, para fazer frente às novas exigências da sociedade moderna.

\section{O Valor da Supervisão}

Quando pensamos no significado da palavra supervisão vem a ideia de que o trabalho do supervisor esteja associado ao controle ou à regulação da qualidade do que o estudante e futuro professor realiza na sala de aula. Para Vieira (2009), quando a supervisão é orientada por uma visão crítica da pedagogia, torna a ação pedagógica mais consciente, deliberada e suscetível à mudança. Esta perspectiva nos revela a possibilidade de pensar a função da supervisão enquanto possibilidade do próprio supervisor refletir sobre sua ação pedagógica. Escreve a referida autora: "Sempre que um educador regula a sua ação (auto-supervisão), as duas atividades fundem-se numa só, tornando-se praticamente indistinguíveis do ponto de vista epistemológico" (VIEIRA, 2009, p. 201).

Sob esse prisma percebe-se que a supervisão incide também de forma direta no próprio trabalho que o supervisor realiza enquanto professor, pois de certo modo, ao supervisionar o fazer dos outros o seu próprio fazer pedagógico também pode ser reavaliado e modificado. Nestes termos a integração entre a prática e as teorias educacionais desvela o valor da supervisão pedagógica e traz à tona também uma possível reavaliação das teorias propagadas nos centros de formação em nível superior.

\section{Para Vieira (2009):}

A finalidade principal da supervisão acompanhada será ajudar os formandos a tornar-se supervisores da sua própria prática e que, se isso 
- Revista de Iniciação à Docência, v. 2, n. 1, 2017 Publicação: dezembro, 2017 - ISSN 2525-4332

não acontecer, falhou no essencial: dotá-los da vontade e capacidade de (re)conceptualizarem o seu saber pedagógico e participarem, individual e coletivamente, na (re)construção da pedagogia escolar (p. 201).

A partir desse excerto entendo que meu trabalho enquanto supervisor do PIBID seguiu muito nessa direção, sempre com o cuidado de supervisionar também a minha própria prática, uma vez que na condição de supervisor meu trabalho servia como referência direta para o fazer docente dos bolsistas. Nessa ação coletiva e compartilhada os bolsistas aprenderam também a importância da avaliação de sua própria ação no espaço da escola, dos impactos que isso trazia em seu processo formativo e sobretudo passaram a questionar a atualidade e o excesso de teorias que são apresentadas na universidade.

De acordo com Morin (2011) esse exercício crítico, que deve acontecer ainda na universidade e nos espaços das experiências de práticas pedagógicas, nos permite civilizar nossas teorias, "desenvolver nova geração de teorias abertas, racionais, críticas, reflexivas, autocríticas, aptas a se auto-reformar" (MORIN, 2011, p. 32).

Durante toda a trajetória que estive trabalhando com os bolsistas sempre nos reuníamos com o propósito de pensar sobre nossa prática na escola, sem perder de vista o que os estudantes discutiam na universidade, buscando estabelecer uma relação direta com o conhecimento acadêmico e com o que o trabalho com as turmas permitia ser realizado.

Partindo desse ponto de vista, o espaço da supervisão não era apenas para acompanhamento e avaliação dos trabalhos desenvolvidos na escola, mas também um ambiente de reflexão sobre todo o processo, inclusive o da formação acadêmica. Desse modo entendo que a supervisão tem uma natureza transformadora e emancipatória, pois permite aos estudantes reconhecer o valor e o limite das teorias, bem como propicia um ambiente fértil para a criação de novas formas de produção do saber e do fazer pedagógico.

\section{Supervisão e Práxis Docente}

Pensar a experiência da supervisão como possibilidade de formação continuada do professor supervisor do PIBID foi algo que despertou meu interesse durante minha trajetória no projeto. Muito embora não seja essa a função do projeto, isto é, oferecer formação continuada aos professores nele engajados, entendo que meu contato com os bolsistas refletiu muito em minha própria atuação enquanto professor. O trabalho de supervisão, que incluía o planejamento das aulas, a elaboração de material didático e a preparação das oficinas era uma excelente oportunidade de aprendizado coletivo, de trocas de saberes e sobretudo de reinterpretação das teorias do conhecimento. 
- Revista de Iniciação à Docência, v. 2, n. 1, 2017 Publicação: dezembro, 2017 - ISSN 2525-4332

Ao adentrar no espaço escolar os estudantes traziam muitas ideias, teorias e questionamentos, o que é positivo, entretanto, prevalecia sempre as dúvidas: como fazer? É possível intervir? São nesses momentos que a experiência do supervisor colabora na formação dos bolsistas. Ao conhecer novos métodos e teorias trazidas pelos estudantes o supervisor aprende e também ensina que "transformar as teorias e práticas pedagógicas implica indagar e refazer o modo como estas forças se (des)articulam ou (re)forçam entre si" (VIEIRA, 2009, p.202).

Neste processo em que desempenhei atividades que estavam para além do que era previsto, vejo que meu papel foi de promover a integração entre a teoria e a prática. É importante destacar também que a articulação do projeto com a proposta pedagógica da escola serviu como um modo de investigação das melhores formas de desenvolvimento e construção do conhecimento, paralelo ao que era trabalhado nas aulas, esse acontecimento, no entanto, só foi possível a partir de minha experiência prévia com a cultura da escola.

Defendo com base em Morin (2011) que o espaço escolar é o lugar da complexidade, do múltiplo, sendo assim, minha atuação junto aos bolsistas sempre foi na direção da interdisciplinaridade e da troca de saberes entre áreas distintas do conhecimento. O fato de não ser historiador e o projeto fazer parte do curso de História já foi um aprendizado significativo para mim, pois me permitiu compreender de forma mais crítica fatos relevantes de nossa história. Aí que reside o sentido da complexidade, que permite a união e a complementariedade de saberes e a educação do futuro se constrói sob o paradigma do conhecimento complexo.

Para Morin (2011):

(...), para a educação do futuro, é necessário promover grande remembramento dos conhecimentos oriundos das ciências naturais, a fim de situar a condição humana no mundo, dos conhecimentos derivados das ciências humanas para colocar em evidência a multidimensionalidade e a complexidade humanas, bem como integrar (na educação do futuro) a contribuição inestimável das humanidades, não somente a filosofia e a história, mas também a literatura, a poesia, as artes... (p. 48).

Trago as considerações do Morin (2011), pois entendo que esse é o momento para pensar e problematizar com os futuros professores a importância de uma educação conectada com o global e as relações entre o todo e suas partes. É imprescindível refletir também sobre meus aprendizados no trabalho de supervisão, meu próprio fazer docente enquanto processo em construção, que por meio do PIBID me mostrou que ensinar também é aprender, compreendo essa disposição para aprender como um dos saberes necessários à prática pedagógica e também como um recurso fundamental para a formação continuada.

Assim, a experiência de supervisão no PIBID configurou-se como um processo formativo no qual não existe uma dissociação entre ser professor e ser supervisor, as 
- Revista de Iniciação à Docência, v. 2, n. 1, 2017 Publicação: dezembro, 2017 - ISSN 2525-4332

coisas acontecem de forma simultânea e para a formação continuada isso implica reflexão e transformações complexas que operam de forma gradual no fazer docente.

Sobre o processo de reflexão sobre a prática que tem implicações diretas na formação continuada, Freire (2011, p. 39) pontua:

Na formação permanente dos professores, o momento fundamental é o da
reflexão crítica sobre a prática. É pensando criticamente a prática de hoje
ou de ontem que se pode melhorar a próxima prática. O próprio discurso
teórico, necessário à reflexão crítica, tem de ser de tal modo concreto que
quase se confunda com a prática. O seu "distanciamento" epistemológico
da prática enquanto objeto de sua análise, deve dela "aproximá-lo" ao
máximo (p. 39).

Com base em Freire (2011) fica evidente a importância da reflexão crítica para a formação, seja ela inicial ou continuada. É interessante pensarmos também sobre o valor das teorias epistemológicas para a prática docente, já que, compreender como elas operam é essencial para entendermos que a educação não se dá no espaço da neutralidade, isso implica reconhecer que ela é ideológica.

Considerando a relevância de uma sustentação epistemológica para a formação do professor, percebo que os textos discutidos nas reuniões com os bolsistas, ou nos planejamentos das oficinas produziram problematizações pertinentes sobre o fazer docente. Lembro por exemplo, de uma situação em que uma bolsista se posicionou de maneira firme em relação a um texto de Antoni Zabala, do livro "A prática pedagógica". Para a bolsista seria tempo perdido discutir o texto, pois segundo ela tudo aquilo era muito distante de nossa realidade.

Considerando os modelos de formação que temos nas universidades, que cada vez mais, priorizam o tecnicismo e a fragmentação do conhecimento, a atitude da bolsista é compreensível e nos coloca um problema que deve ser discutido dentro e fora da universidade. "Esse modelo aplicacionista não é somente ideológico e epistemológico, é também um modelo institucionalizado através de todo o sistema de práticas e de carreiras universitárias" (TARDIF, 2000, p. 18).

Do ponto de vista epistemológico, temos uma situação em que a bolsista procura sempre fazer uma relação da teoria com a prática por meio de relações concretas e aplicadas. Em se tratando de minha função enquanto supervisor, percebo o quanto a formação continuada associada a prática docente pode esclarecer as confusões epistemológicas tão comuns aos iniciantes da profissão de professor.

Sobre a importância de uma epistemologia para sustentar a prática profissional, Tardif (2000) salienta que:

A finalidade de uma epistemologia da prática profissional é revelar esses saberes, compreender como são integrados concretamente nas tarefas dos profissionais e como estes os incorporam, produzem, utilizam, aplicam 
- Revista de Iniciação à Docência, v. 2, n. 1, 2017 Publicação: dezembro, 2017 - ISSN 2525-4332

e transformam em função dos limites e dos recursos inerentes às suas atividades de trabalho. Ela também visa a compreender a natureza desses saberes, assim como o papel que desempenham tanto no processo de trabalho docente quanto em relação à identidade profissional dos professores (p. 11).

O reconhecimento de uma certa unidade entre teoria e prática e suas implicações no fazer docente discutidos no âmbito da supervisão, introduz dispositivos de formação que implica na consolidação de saberes para os bolsistas e orienta o supervisor sobre os cuidados necessários e indispensáveis à sua prática cotidiana. Nessa perspectiva a supervisão está para além do suporte que é dado ao trabalho prático que os bolsistas desenvolvem em sala de aula, ela funciona como um dispositivo de formação inicial para os bolsistas e continuada para o supervisor.

\section{Iniciação à Docência: um caminho possível para aprender ensinar e a ser professor}

Nos últimos anos temos presenciado um crescimento significativo de investimentos que buscam melhorias no campo da atuação docente. As conquistas recentes devem muito às articulações dos sindicatos dos trabalhadores em educação em todo país e sobretudo da política de valorização da educação pública capitaneada pelos governos do Partido dos Trabalhadores (PT).

No âmbito do governo federal programas voltados para a melhoria da ação docente, tais como a formação oferecida aos professores que fazem parte do Pacto Nacional pela Alfabetização na Idade Certa (PNAIC), e o Programa Institucional de Bolsas de Iniciação à Docência (PIBID) promovem um espaço formativo no qual os professores já em exercício refletem, aprendem e aperfeiçoam sua prática e os estudantes de graduação, no caso dos bolsistas de iniciação à docência, consolidam novas aprendizagens que serão necessárias à sua futura prática docente.

As estratégias formativas supracitadas, dentre muitas outras, fazem parte de um conjunto de medidas que visam a configuração de um novo cenário profissional para os professores em exercício, bem como para os que pretendem aderir a carreira docente, além disso, promovem o conhecimento de novos aprendizados fundamentais à prática profissional, o que permite o fortalecimento de culturas pedagógicas inovadoras e isso, claro, não pode ser efetivado sem a parceria do poder público. Sobre isso Soares e Vieira (2014) acrescentam que:

A construção de culturas pedagógicas mais transformadoras exige não só a iniciativa dos docentes, mas também medidas institucionais de apoio ao ensino, por meio de políticas de incentivo à inovação e ao desenvolvimento profissional, com a criação de centros de assessoria pedagógica, financiamento de projetos de investigação pedagógica, apoio a publicações sobre pedagogia e dinamização de fóruns pedagógicos (p. 1691700. 
- Revista de Iniciação à Docência, v. 2, n. 1, 2017 Publicação: dezembro, 2017 - ISSN 2525-4332

O que as autoras propõem é uma formação que se coloque a serviço da aprendizagem e do desenvolvimento profissional dos professores. Nessa perspectiva, o PIBID, por meio de suas atividades práticas com os bolsistas caminha nessa direção, uma vez que as intervenções no espaço escolar, seguidas das reuniões de supervisão são tidas como experiências que potencializam o que é aprendido na universidade.

Pensar o conhecimento nessa perspectiva, na qual ele está diretamente associado às experiências implica assumir uma posição epistemológica, a qual considera que o distanciamento entre teoria e prática, conhecer e fazer culminam na falta de conexão entre o saber e o fazer. Enquanto supervisor do PIBID sempre busquei estabelecer essas relações entre conhecimento e experiência, na tentativa de reafirmar o valor das teorias educacionais sempre as associando às situações da vida prática. Sendo assim, "quando o conhecimento é afastado da função de fornecer significado ao que está obscuro e confuso, ele se separa inteiramente da consciência ou, ainda, torna-se um objeto de contemplação estética" (CUNHA, 2007, p.101-102).

De acordo com Cunha (2007), só é realmente conhecimento aquilo que nos permite adaptar o ambiente às nossas necessidades e nossos objetivos e desejos a situação em que vivemos, logo o conhecimento é útil quando dá direção e significado as nossas vidas. De acordo com Cunha (2007):

\footnotetext{
Conhecimento é o que se organiza diante de uma situação problemática que envolve o indivíduo e o ambiente, o intelecto como ferramenta reflexiva e as impressões oriundas do meio circundante; sua função é sistematizar as possibilidades de intervenção nessa realidade concreta, com o intuito de adequar reciprocamente os componentes individuais e ambientais (p. 105).
}

Essas considerações sobre a natureza do conhecimento e o valor da experiência, no contexto do PIBID, são salutares quando pensamos na proposta do projeto, que permite aos bolsistas um contato com a prática em espaços escolares, muito antes dos estágios obrigatórios que são comuns às licenciaturas. 0 enfrentamento dessa experiência, que faz parte do processo formativo revela aos bolsistas peculiaridades importantes da profissão docente.

Em virtude desse contato antecipado com a prática pedagógica os bolsistas têm a oportunidade de vivenciar suas ansiedades e inseguranças longe do crivo da avaliação dos estágios supervisionados. Esse contato prévio com o ambiente escolar permite que os bolsistas visualizem de perto os dilemas da profissão de professor, a relação com os alunos e destes com os professores, as questões burocráticas, dentre outros fatores presentes nas escolas, que outrora só eram sentidos no momento do estágio.

Fazendo uma relação com os estágios supervisionados nota-se que a proposta do PIBID minimiza o "choque" que muitos estudantes enfrentam nas escolas, bem 
- Revista de Iniciação à Docência, v. 2, n. 1, 2017 Publicação: dezembro, 2017 - ISSN 2525-4332

como favorece a socialização com a cultura escolar. Este processo estimula reflexões aprimoradas sobre as experiências vivenciadas no contexto escolar e essas passam a ser incorporadas à prática pedagógica desses futuros professores.

No que tange às contribuições formativas do PIBID, o Programa funciona como uma oportunidade de integração entre a cultura universitária e a cultura escolar, além de ser um dispositivo que amplia as potencialidades dos bolsistas nos momentos dos estágios. Paralelo a este aspecto, permite aos estudantes pensar a teoria como instrumento de compreensão e intervenção em situações concretas, sem perder de vista a importância que os estágios propriamente ditos fazem no processo de profissionalização docente.

Sobre a importância dos estágios para a formação docente Andrade (2005) pontua que:

O Estágio permite a integração da teoria e da prática e é o momento de
concretude da profissão. É, portanto, uma importante parte integradora
do currículo, em que o licenciando vai assumir, pela primeira vez, a sua
identidade profissional e sentir, na pele, o compromisso com o aluno, com
sua família, com sua comunidade, com a instituição escolar, que representa
a inclusão civilizatória de vastas camadas da população; com a produção
conjunta de significados em sala de aula; com a democracia, com o sentido
de profissionalismo que implique competência, isto é, - fazer bem o que
lhe compete (p. 24).

Frente ao exposto, observa-se que o PIBID desempenha uma função preponderante no processo de profissionalização dos futuros professores, pois antecipa vivências que possibilitam a formação da identidade profissional dos professores. Neste contexto os bolsistas têm a oportunidade de discutir problemas comuns ao cotidiano escolar, aprender novos conhecimentos e métodos e, com isso, ter a opção de decidir antes dos estágios se é realmente a carreira docente que pretende seguir.

\section{Considerações Finais}

De acordo com Tardif (2000) a profissionalização docente ocorre num processo que contempla experiências e saberes diversos, que vão garantindo ao professor o domínio do trabalho e de si mesmo. Partindo dessa perspectiva há de se considerar que o início da docência precisa ser tomado como um momento de investimento significativo na vida dos futuros professores.

Conforme Costa e Oliveira (2007) argumentam:

A iniciação na docência tem se revelado como uma etapa importante no processo de aprender a ser professor. Diante de uma realidade complexa, muitas vezes o professor se desestrutura, pensa em desistir da profissão, sente-se como um estranho no ambiente escolar, duvida da sua competência e da importância da formação inicial. Enfim, para aqueles que 
- Revista de Iniciação à Docência, v. 2, n. 1, 2017 Publicação: dezembro, 2017 - ISSN 2525-4332

permanecem, é uma fase que contribui de maneira singular para uma determinada forma de ser professor (p. 28).

Diante disso, podemos pensar que o PIBID representa uma estratégia formativa que orienta os bolsistas em sua trajetória profissionalizante, soma-se a isso também o fato dos integrantes serem contemplados com uma bolsa no valor de $\mathrm{R} \$ 400,00$ reais que os auxilia em sua renda mensal, permitindo aos mesmos a participação em eventos, compra de livros e materiais didáticos e, em alguns casos, a manutenção de necessidades básicas como moradia e alimentação.

Importante também salientar, que frente ao momento político de redução de direitos e cortes de investimentos em programas sociais e educacionais que atravessa o país, é necessária a articulação da universidade com a sociedade de modo que programas como o PIBID sejam preservados e incentivados.

As vivências no contexto da escola junto aos bolsistas me revelou a importância da necessidade de investimentos por parte do poder público no que tange às políticas educacionais para a formação de professores. Ao trabalhar as peculiaridades do fazer docente junto aos bolsistas, em formação inicial tive a oportunidade de esclarecer para eles que educação é um processo que se dá na práxis, no corpo a corpo, e que as teorias educacionais vistas nos meios acadêmicos precisam dialogar e intervir na vida cotidiana dos professores, dos estudantes e sobretudo na vida dos que estão em processo de formação.

Diante das reflexões aqui apresentadas defendo a permanência e a ampliação do PIBID como uma política pública de formação inicial que se articula diretamente com a formação continuada dos professores nele envolvidos. Nesse processo é necessário considerar que "a formação em nível superior, coloca-se como uma bandeira a ser implementada pela democratização do acesso, da permanência e da gestão desse nível de ensino como caminho fértil para a formação e a profissionalização" (DOURADO, 2011, p. 56).

Neste cenário fica evidente que o PIBID, enquanto política pública, configurase como um grande avanço no campo de formação e profissionalização dos futuros professores, servindo como um elo que aproxima as universidades das escolas e promove um espaço de trocas e aprendizados, e que infelizmente, assim como outros programas vem sofrendo os entraves das mudanças de ordem política e institucional que compõem a reforma de Estado implantada no país.

\section{Referências}

ANDRADE, A. O estágio supervisionado e a práxis docente. In: SILVA, M. L. S. F. (Org.). Estágio curricular: contribuições para o rendimento de sua prática. Natal: Editora da UFRN, 2005, p. 21-26. 
- Revista de Iniciação à Docência, v. 2, n. 1, 2017 Publicação: dezembro, 2017 - ISSN 2525-4332

COSTA, J. S.; OlIVEIRA, R. M. M. A. de. A iniciação na docência: analisando experiências de alunos professores das licenciaturas. Olhar de professor, v. 10, n. 2, 2007, p. 23-46.

CUNHA, M. V. John Dewey - Democracia e Educação: capítulos essenciais. São Paulo: Ática, 2007.

DOURADO, L. F. A reforma do Estado e as políticas de formação de professores nos anos 1990. In: DOURADO, L. F.; PARO, V. H. (Orgs.). Políticas públicas e educação básica. São Paulo: Xamã, 2011, p. 49-57.

FREIRE, P. Pedagogia da autonomia: saberes necessários à prática pedagógica. São Paulo: Paz e Terra, 2011.

MORIN, E. Os sete saberes necessários à educação do futuro. São Paulo: Cortez, 2011.

SOARES, S. R.; VIEIRA, F. Aprendizagem, ensino e desenvolvimento profissional docente na universidade: desafios, perspectivas e trajetórias de mudança. In: Revista da FAEEBA - Educação e Contemporaneidade, v. 23, n. 41, p. 165-177, jan./jun. Salvador, 2014.

TARDIF, M. Saberes profissionais dos professores e conhecimentos universitários Elementos para uma epistemologia da prática profissional dos professores e suas consequências em relação à formação para o magistério. Revista Brasileira de Educação, n. 13, 2000. n. 13, p. 5-24,

VIEIRA, F. Para uma visão transformadora da supervisão pedagógica. Educação e Sociedade, v. 29, n. 105, p. 197-217, jan. /abr. Campinas, 2009. 